X.

Aus der medizinischen Universitätsklinik (Geh. Rat Prof. Dr. Krehl) und der biologischen Abteilung (v. Dungern) des Krebsinstitutes (Exzellenz Geh. Rat Czerny) zu Heidelberg.

\title{
Beiträge zur Kenntnis der Diphtherievergiftung und ihrer Behandlung ${ }^{1}$ ).
}

\author{
I. Teil.
}

Von

Priv. Doc. Dr. Fritz Meyer-Berlin.

(Mit 13 Kurven.)

Die Diphtherievergiftung ist durch $\nabla$. Behrings und Löfflers grundlegende Arbeiten ein für Meusch und Tier wohlcharakterisiertes Krankheitsbila geworden.

Seit der Darstellung des Diphtheriegiftes durch Roux und Aronson wissen wir, daß weitaus die meisten der beobachteten Erscheinungen als Giftwirkungen aufuufassen sind. So ist die Behandlung der mensehlichen Diphtherie eine rein antitoxische geworden und Frankreich und Italien sind vorerst die einzigen Länder, welche an der Notwendigkeit einer gemiseht bactericid-antitoxischen Serumtherapie festhalten.

Mit dem Ausbau der Antitoxinlehre durch Ehrlich und seine Schüler wurde der grundlegende und für die ganze Immunitätslebre bedeutungsvolle Satz Allgemeingut: daß lediglich der Gehalt an Immunitätseinheiten den Heil- und Schutzwert eines Serums bestimmt.

Bei einer solchen, bis ins kleinste ausgearbeiteten Lehre, welche hinsichtlich ihrer Folgesicherheit in der Geschichte der Medizin einzig dasteht, ist es auffallend, daß die experimentellklinische Beobachtung in den letzten Jahren entschieden vernachlässigt worden ist. Diese Tatsache ist nur so zu erklären, daß sieh die Arbeit an den Fundamenten eines Baus, dessen Schlußsteine vollendet zu sein scheinen, selten der Mühe lohnt.

Die vorliegenden Untersuchungen haben es sich zum Ziele gesetzt, unter voller Anerkennung der von v. Behring und Ebrlich ausgesproehenen Seblußsätze, den Symptomenkomplex der experimentellen Diphtherievergiftung zu studieren und unter Berücksichtigung

1) Der medizinischen Fakultăt als Habilitationsschrift eingereicht im April 1908. 
Beitrăge zur Kenntnis der Diphtherievergiftung und ihrer Behandlung. 209

klinischer und anatomischer Fakta die Erfolge der spezifischen und symptomatischen Behandlung genauer zu begrenzen. So sollen im vorliegenden ersten Teile die Wirkung der Diphtherietoxine auf Blutdruck, Komplementgehalt und Blutkörperehen, glcichzeitig die Heilwirkung des Diphtherieantitoxins betrachtet werden, während der nächste Absehnitt sich vornehmlich mit den anatomischen Grundlagen der Intoxikationssymptome za beschäftigen haben wird.

I.

Einwirkung des Diphtherietoxins auf den Blutdruck.

Die Beobachtung der so häufig bei schweren menschlichen Diphtherievergiftungen auftretenden Blässe mit hochgradiger Pulsbeschleunigung führte vor schon längerer Zeit Romberg (1) und Pässler (2), v. Ste ysk a l (3) und jüngst Rolly (4) und Jwanowa (5) zu Untersuchungen, welche sieh mit den Veränderungen des Blutdruckes an Diphtherie-vergifteten Tieren beschäftigen. Während alle übereinstimmend ein starkes Sinken des Blutdruckes, bis zu minimalen Werten kurz vor dem Tode, konstatierten, weichen die Erklärungen der einzelnen Autoren in der Deutung und Lokalisation der dafür anzuschuldigenden Ursache beträchtlich von einander $a b$. Romberg, Pässler, Gottlieb (6) und Rolly, suchen den Grund in einer Läbmung: der Gefäßzentren, weleher sich erst sehr spät eine sekundäre Schädigung des Herzens zugesellt.

Demgegenüber vertritt v. Steyskal die Ansicht einer primären Schädigung des Herzens und sieht in dieser die Ursache des Diphtherietodes. Bis auf Romberg, weleher lebende Kulturen einspritzte, hatten alle Autoren mit bakterienfreien Giften gearbeitet und gefunden, daß nach einer variablen Latenzzeit von zirka 24-50 Stunden der Druck zu fallen beginnt, um kurz vor dem Tode unmeßbar klein zu werden. Medikamente sind nur ganz vorïbergehend imstande, Hebungen herbeizuführen, während aus begreiflichen Gründen Versuche mit Antitoxinseris nicht gemacht worden sind. Die nachfolgenden Untersuchungen wurden unabhängig von der Frage, worin die Ursache der Drucksenkang zu suchen ist, angestellt.

Immerhin sprechen viele der von uns gefundenen Fakten zugunsten der Rombergschen Ansicht.

Bei Ausfuhrung der Blutdruckversuche haben mich die Herren Gottlieb, Magnus und Morawitz in liebenswürdigster Weise unterstützt. 
Unsere Versuche sollten entscheiden

1. wann der Abfall des Druckes eintritt,

2. wann eine spezifische Behandlung eingeleitet werden muß, um den Abfall zu verhüten.

3. vor allem, ob es durch spätere Einverleibung von Antitoxin noch gelingt, die ominöse Drucksenkung hinauszuschieben.

$\mathrm{Zu}$ diesen $\mathrm{Zw}$ weken wurden drei verschiedenartige Versuchsanordnungen angewendet.

a) Zunächst wurden Tiere mit einer in drei Tagen zum Tode führenden Giftdosis injiziert und Druckmessungen zu verschiedenen Zeiten angestellt.

b) Unter Kontrolle des Blutdrucks wurden Seruminjektionen in wachsender Größe ausgeführt.

e) Schließlich wurden Spätinjektionen unter Variierung der Serumdosis gemacht und am schwerkranken Tiere die versehiedenen, in der menschlichen Therapie gebränchlichen Medikamente geprüft.

Die Versuchsanordnung war folgende:

Das uns von der bakteriologischen Abteilung der Höchtser Farbwerke gütigst zur Verfügung gestellte Diphtheriegift war ein toluolisiertes Bouillongift, welches in der Dosis von $3 \mathrm{mg}$ Meerschweine in 5 Tagen tötete. Ein Zentigramm desselben Giftes wirkte subkutan injiziert, tödlich in 48 Stunden, und eben die gleiche Dosis tötete Kaninchen auf intravenösem Wege in 3-4 Tagen. Diese Angabe bestätigt die schon früber gefundene Tatsache, dab die für Meerschweine in 2 Tage tödliche subkutane Dosis in der Regel auch für Kaninchen bei intravenöser Einspritzung die entsprechende tödliche Dosis darstellt. Die von uns gegebenen Mengen variieren zwischen 1-6 zentigramm, während darauf gehalten wurde, nur Kaninchen von durehschnittlich $2000 \mathrm{~g}$ zu verwenden. 24 Stunden nach der Giftinjektion wurden die ersten Druckmessungen ausgefuhrt und in 12-24 stündigen Abständen wiederbolt. Die Operation bestand in der Freilegung der Carotis in Urethannarkose, so lange die Tiere noch munter waren, und Verbindung des Blutstroms dureh ein mit halbgesättigter Natriumsulfatlösung gefülltes Rohr mit dem Manometer. Wir wendeten diese, sonst nur in England gebrauchte gerinnungshemmende Flüssigkeit deshalb ausschließlich an, weil Diphtheriekaninchen eine große Empfindlichkeit gegenüber den sonst gebräuchlichen Magnesiumsulfatlösungen zu besitzen scheinen. Schon Mengen von $1-2 \mathrm{ccm}$, welehe leicht in die Zirkulation geraten können, genügen um den sofortigen Tod des Tieres herbeizufübren. 
Da es uns nur darauf ankam, die absolute Druckhöhe zu finden, wurde die Operation so schnell als möglich ausgeführt und nicht länger als 5-10 Minuten ausgedehnt. Die Tiere vertrugen diesen Eingriff ohne jeden Schaden und begannen kurz nach ihm wieder zu fressen. Das Beispiel eines solchen Versuches stellt sich folgendermaßen dar:

Kaninchen Nr. 35 Gew. 2050 g erhält:

am 13. 3. 0,03 Toxin subkutan, Druek 98

$\begin{array}{lll}14.3 . & & 80 \\ & 15.3 . & \end{array}$

Tod in der Nacht vom 15. 3. zum 16. 3.

Die so festgestellte, allmählich cintretende Drucksenkung, welche in der Regel 24 Stunden, manchmal bei entsprechend kleiner Dosis erst 36 Stunden nach der Einverleibung des Giftes beginnt, ist zunächst nicht mit klinischen Krankheitssymptomen verbunden. Allein die dünne und kollabierte Beschaffenheit der Carotis zeigt sie schon bei der vorbereitenden Operation an. Die Tiere sind zu dieser Zeit noch munter und baben keinerlei Gewichtsverluste. Erst 20 Stunden vor dem Tode beginnt eine starke Pulsbeschleunigung, welche kurz vor dem Tode in Pulsverlangsamung übergeht, die Haare werden struppig, die Haltung ist eine auffallend rubige, zusammengedukte, die Augen bleiben halb geschlossen. Die Respirationszahl fängt an zu steigen und erreicht doppelt so große Werte als normal. 2 Stunden vor dem Ende legen sich die Tiere auf die Seite und beginnen zu taumeln, bis häufig unter Krämpfen und Schreien, unter stockender Respiration und sinkender Pulsfrequenz, der Tod eintritt. Der Druck fällt in dieser letzten Periode, wie man sich am Manometer uberzengen kann, dauernd bis zum Tode, doch konnten wir Rollys Angabe: daß in dieser letzten Stunde die Drucksenkung bei der normalen Höhe beginne, dahin ergänzen, daß eine langsame, jedoch meßbare Verringerung sich schon nach einer Latenzzeit von 24 Stunden geltend macht und bis zum Ende fortschreitet. Die Differenz unserer und der Rollyschen Versuche erklärt sich durch die Tatsache, daß Rolly mit Giften gearbeitet hat, welehe den Tod der Tiere erst in verhältnismäßig großen Dosen herbeiführten, so daß die von uns verwendeten Mengen gegentiber den seinigen sich wie $1: 10$ oder $1: 20$ verhielten. Dadurch wird das von uns in mehreren Tagen verfolgte Stadium der klinisch-manifesten Vergiftung auf das Zeitmaß einer Stunde herabgesetzt, während die Latenzzeit, d. h. die Periode der Giftbindung an die Organzellen nicht wesentlich differiert. Im folgenden werden uns diese Begriffe noch häufiger 
zu beschäftigen haben, da gerade bisher auf die zeitlichen Verhältnisse dieser beiden wichtigen Perioden der Diphtherievergiftung im Gegensatz zum Tetanus - nur wenig Wert gelegt worden ist.

Ohne vorerst die Frage zu entscheiden, ob die Schädigung des Herzens oder der Gefäßzentren die primäre Ursache der Druckverringerung darstellt, war es wichtig, festzustellen, ob die spezifische Antitoxinbehandlung imstande sei, diese Erscheinungen
a) anfzuheben,
b) zu verbindern,
c) \%u verzögern.

Der schwierigste und zugleich wichtigste Erfolg wäre es zweifellos, wenn es gelänge, durch große Mengen Serum Tiere, welche sich sehon auf der absteigenden Linie befinden, soweit zu heilen, daß sich der Blutdruck wieder zu heben beginnt. $\mathrm{Zu}$ diesem Behufe wurden folgende Versuche angestellt:

13. 2. Kaninchen Nr. 40, Gew. 2010 g, erhält intravenös 0,02 Toxin Vormittags 11 Uhr Druck 106

14. 2. Nachmittags $5 ", \quad$ noch 80

Das Tier erhält 3000 A. E. Höchster Serum (400 fach)

15. 2. Morgens ist der Druck nur noch $50 \mathrm{~mm}$.

Abends tritt der Tod unter den bekannten Zeichen der Kreislaufschwäche ein.

Um zu entscheiden, ob es möglich sei, durch frühzeitigere Seruminjektion bei noch nicht verändertem Druck einen beilenden Einfluß auszuüben, wird der Versuch so modifiziert, daß die Seruminjektion 5 Stunden nach der Giftinjektion verabfolgt wird. Doeh auch dabei war es nicht möglich, Tod und Drueksenkung auch nur nennenswert hinauszuschieben, vorausgesetzt, daß das Gift intravenös einverleibt worden war.

Bedentend erfolgreicher waren unsere Bestrebungen, durch frühzeitige Serumbehandlung die Drucksenkung zu vermeiden und, wenn dies nicht mehr gelang, hinauszuschieben.

Versuch: Kaninchen a, b und c zirka $1800 \mathrm{~g}$ schwer, erhalten 0,04 Toxin am 13. 1. um 5 Uhr 20 Min. nachm. subkutan. Kaninchen b erbält nach 6 Stunden 1000 A.E. I) Höchst. Serum. Kaninchen c enthält nach 6 Stunden 500 A. E. Höchst. Serum.

14. 1. waren die Druckzahlen von a, b und c $70-100-96 \mathrm{~mm}$.

15. 1. Kaninchen a stirbt, bevor der Versuch beendet ist, während $b$ und $e$ Werte von 80 und 94 aufweisen.

16. 1. wurden keine Messungen gemacht und am

17. 1. Morgens starben beide Tiere.

1) A. E. = Antitoxin-Einbeit. 
Bei weiterer Verkürzung der zwischen Gift- und Serumdarreichung liegenden Frist gestaltete sich der Versuch zu einem völlig gelungenen, da bei einer nach 4 Stunden verabfolgten Serummenge von 1000 A. E. der Druck am nächsten Tage normale Werte zeigte und das Tier dauernd am Leben bleibt.

\section{Versueh:}

Kaninchen 30 und 31 erhalten am 20. 1. nachm. 3 Uhr je 0,04 Toxin subkutan.

Kaninchen 31 um 7 Uhr 1000 A. E. Sernm intraperitoneal. Der Druck ist nach 24 Stunden 90 und am Todestage des Kontrolltieres Nr. 30 sogar $96 \mathrm{~mm}$ Hg.

Kaninchen 31 wird nach 3 Wochen bei völligem Wohlbefinden getötet und zeigt völlig normale Organe (Herz, Leber, Nieren und Nebennieren).

Wenn diese Versuche nicht schon zur Genïgen den kurativen Einfluf des Antitoxins zeigten, ist folgender Befund besonders geeignet die Wirkung des Antitoxins zu beweisen, da der erstrebte Heilungseffekt sogar von der eingefübrten Menge des Serums abhängig ist. Gleichzeitig sehen wir, welch feinen Gradmesser der Vergiftung wir in der Blutdruckmessung besitzen.

Versuch:

6. 3. erhalten Kaninchen $d$, e und $\mathbf{f}$ je 0,03 Toxin intravenös. Kaninchen e nach 1 Stunde 1 A. E. Serum

$$
\begin{aligned}
\text { 7. 3. betragen die Werte des Druckes für } \mathrm{d} & =64 \text { (+ nach } 40 \mathrm{Std} \text {.) } \\
\text { für } \mathrm{e} & =80 \text { (+ nach } 71 \text { Std.) } \\
\text { fïr } \mathrm{f} & =110 \text { (bleibt am Leben). }
\end{aligned}
$$

Dieser Versuch soll im Abschnitt der objektiven Heilversuche durch Serum, ausführlich besprochen und hier nur dahin gedeutet werden, daß nicht nur das Serum als solches von großer Bedeutung für die Hintanhaltung der ominösen Drucksenkung zu betrachten, sondern auch je nach der Größe der verwendeten Dosis diese Verzögerung zu einer völligen Ausgleichung zu machen imstande ist. Können wir somit, wie es bisher den Ansehein hat, niemals einen schon im Absteigen begriffenen Blutdruck durch die größten Serumdosen auf die normale Höhe bringen, so gelingt es doch, die Drucksenkung, selbst durch zu spät verabfolgtes Antitoxin hinauszusehieben, durch rechtzeiti'g gegebenes dauernd zu vermeiden.

Für dieses Ergebnis ist sowohl der Umstand, daß das Antitoxin intravenös, als auch in gehöriger Menge verabfolgt wird, von entscheidender Bedeutung.

Um jedoch im Binblick auf die schwere menschliche Diphtherie, bei weleher von Antitoxin keine momentane Wịkung zu erwarten 
ist, nicht völlig dem Negativismus zu verfallen, versuchten wir einige der gebräuchlichen Medikamente in ihrer Wirkung auf das

\section{Kurve I.}

Einfluf der Serumbehandlung auf die Blutdrucksenkung nach verschiedenen Zeiten. Nach 24 Stunden.

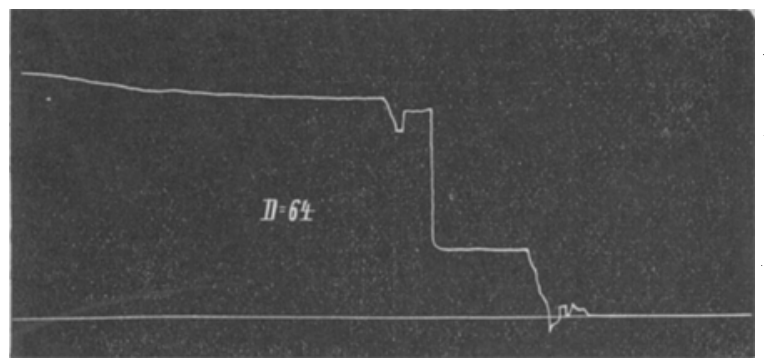

Toxin 0,03 intravenös am 13. 3.

(Kaninchen $65,66,67$.

K. 65 Kontrolltier

Tod nach 10 Stunden ohne Serum

Blutdruck am 14. 3 .

5 Ohr.

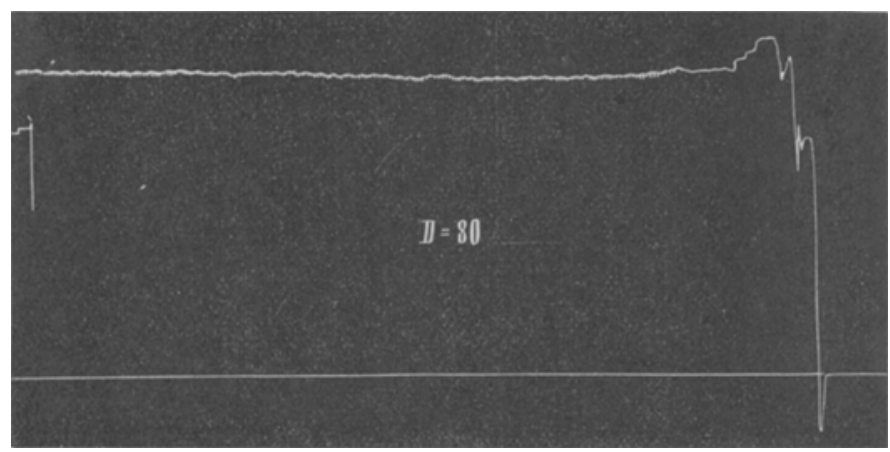

K. 66 Blutdruck am 14. 3 .

(51/2 Uhr) erhielt

1 Stunde nach der Giftinjektion 1 A. E. $+16.3$.

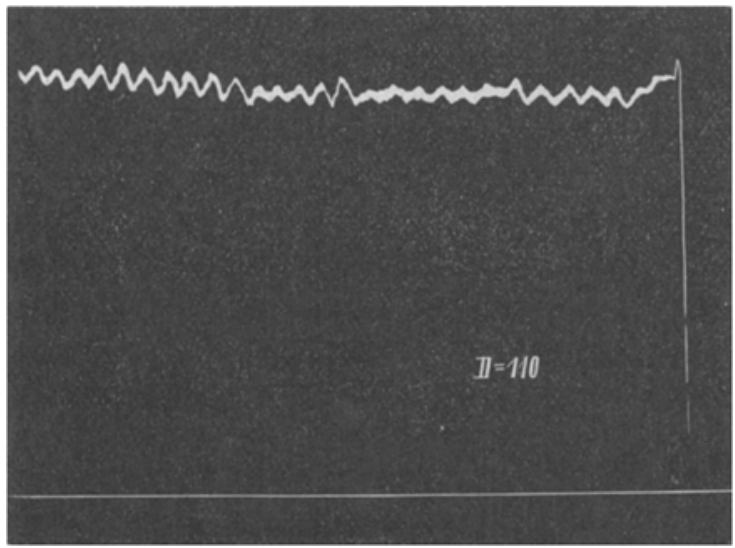

K. 67 am 14. 3.08

6 Uhr erbielt nach 1 Stunde $400 \mathrm{~A}$. E. gesund getötet 20.3. 08 .

Diphtherie-vergiftete, sterbende Tier, dessen Blutdruck bis auf $40-20 \mathrm{~mm} \mathrm{Hg}$ herabgesunken war. Es wurden in wechselnder Reihenfolge angewendet: Coffeinum natrio-benzoicum, Digalen, 
Strophanthin, Tet. Moschi, Aether, welche sämtliche mit Ausnalime des letztgenannten intravenös verabreicht wurden.

Kurze und sebr geringfügige Steigerungen wurden nach allen beobachtet (Steigerungen von 20 auf $40 \mathrm{~mm}$ usw.), doch waren die damit verbundenen Besserungen der Atmung und des Pulses so unbedeutend, daß irgend welcher Nutzen für die menschliche Therapie sich nicht dabei ergeben dïrfte. Allein Coffein und Strophanthin scheinen wirksame Stoffe darzustellen, da ein 1 Zentigramm resp. Dezimilligramm derselben eine Steigerung um $50 \mathrm{~mm} \mathrm{Hg}$ für die

Kurve I.

Nach 72 Stunden.

\section{Kontrolltier seit 40 Stunden tot. Blutdruck am 16.3. K. 66 \\ 6 Stunden vor d. Tode.}

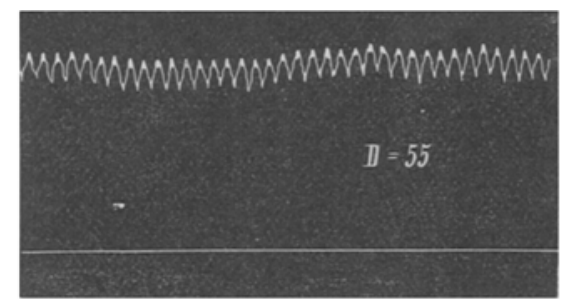

\section{K. 67}

16. 3 .

bleibt am Leben.

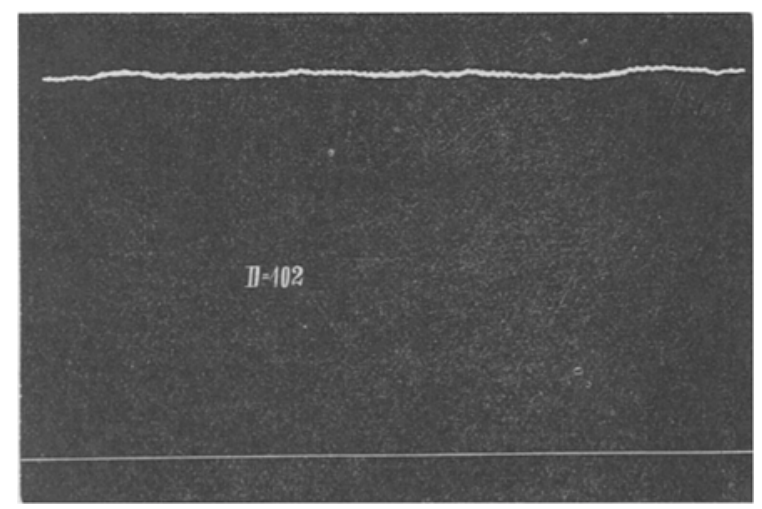

Dauer einer Viertelstunde bewirkten. Im ganzen wären diese nicht sehr ermutigenden Resultate die gleichen, wie sie ron Paeßler und Iwanova schon früher veröffentlicht wurden; wenn nicht die letzten Wochen uns in einer neuen Behandlungsart Erfolge gegeben hätten, welche für die Behandlung des Collapses bei Infektionskrankheiten von großer Bedeutung zu sein scheinen.

Von der Beobachtung ausgehend, daß gerade bei der experimentellen Diphtherie die Nebennieren besonders charakteristische Veränderungen (Blutungen) aufweisen, versuchten wir durch In 
Kurve 11 .

Einfluß der 1 Stunde $30^{\circ}$ nach der Giftinjektion eingeleiteten Serumbebandlung auf den Blutdruck, gemessen nach 33 Stunden.

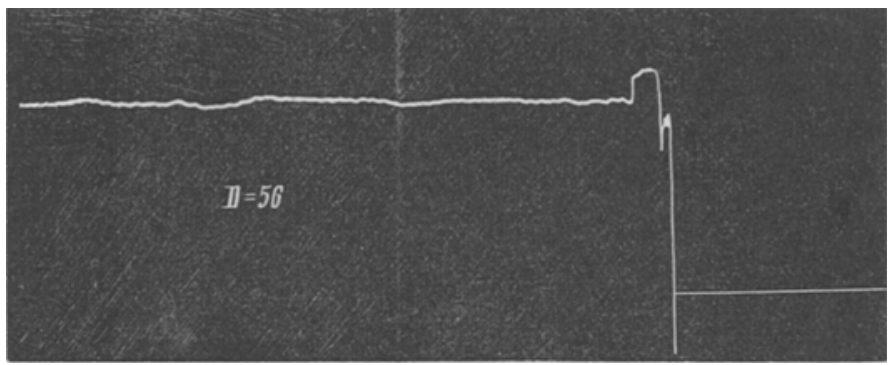

K. 69. (17. 3. 08 abds.) Obne Serum.

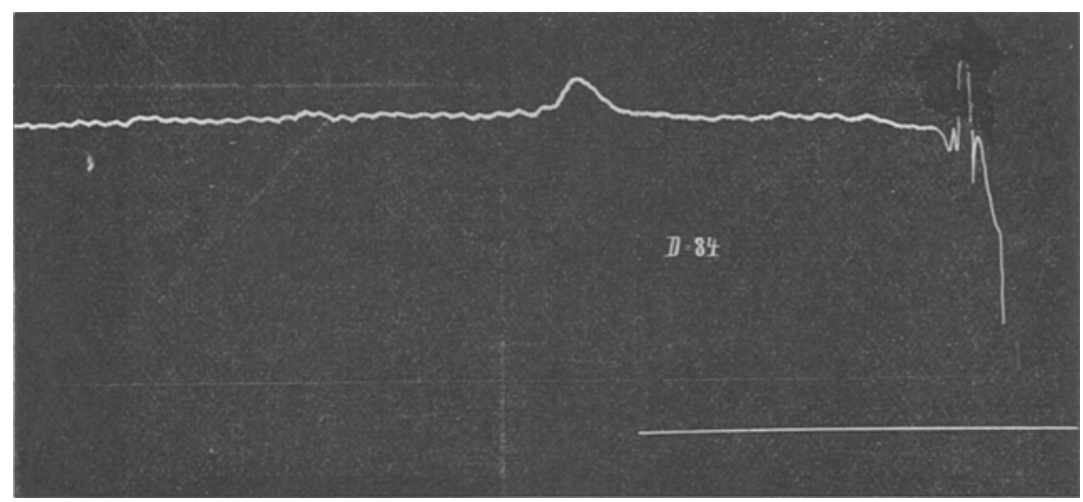

K. 70. (17. 3. 08. abends) 6 Uhr. 1 A. E.

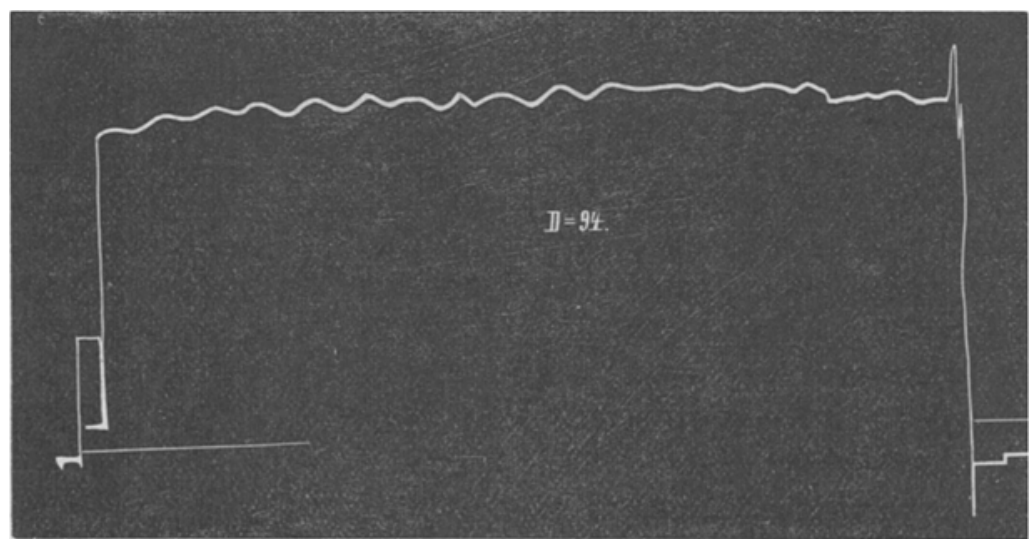

K. 69. 17. 3. 08 , abends 7 Uhr. 400 A. E. 
Beiträge zur Kenntnis der Diphtherievergiftung und ihrer Bebandlung. 217

jektionen von Suprareninum hydrochloricum (Höchst) den schweren Collaps unserer Versuchs-Tiere zu bekämpfen. Diese Versuche hatten günstige Ergebnisse besonders, als wir von der durch Haidenhain (7) inaugurierten Therapie der Perforatiosperitonitis beim Mensehen, durch intravenöse Adrenalin-Kochsalzinjektionen Kenntnis erhielten. Dieses Verfahren, von Heineke (8) und Rothsehild (9) erprobt, lieferte uns erstaunliche Resultate. Tiere, welehe mit einem Blutdruck von $30-40 \mathrm{~mm} \mathrm{Hg}$ an das Kymographion gebracht wurden, bekamen $5 \mathrm{ccm}$ einer Adrenalin-Kochsalzlösung $(0,025: 50,0)$ intravenös und hielten sich 30-40 Minuten auf Druck-Höhen von $110-120 \mathrm{~mm} \mathrm{Hg}$ (Kurve III). Damit ging eine evidente Besserung der Atmung und Pulsbeschleunigung von 40 auf 90 Schläge einher. Cornealreflexe, welche schon erloschen waren, wurden wieder rege und Tiere, welche moribund waren und in Seitenlage verbarrten, richteten sich auf, um erst nach 7 Stuuden zu sterben. Wir besitzen demnach in dieser Behandlungsart eine Möglichkeit momentan eine durch nichts anderes erreichbare Wirkung zu erzielen - eine Tatsache, welche dieser Methode einen. Platz in der Therapie schwerer mensehlichen Diphtherien mit Sicherheit in Aussicht stellt.

\section{II,}

Heilungsversuche mï Höchster Diphtherieheilserum.

(v. Behring, Ehrlich).

Die nachfolgenden Versuche wurden angestellt, um zu eruieren, wie weit das Diphtherieheilserum, welches den Typus eines rein antitoxischen Serums darstellt, befähigt ist, bestehende Vergiftungen zu beilen. Es sei daher an dieser Stelle gestattet kurz darauf hinzuweisen, wie der Vorgang einer Serumheilung zu denken ist: Anschauungen, welche ausschließlich den genialen Ehrlichschen Forschungen zu danken sind.

Je nachdem das Toxin fertig oder in Gestalt der giftproduzierenden Bazillen (lebende Kultur) eingeführt, je nachdem es auf intravenösem oder subkutanem Wege dem Tiere einverleibt wurde, muß man zwischen einer quantitativ begrenzten oder unbegrenzten Vergiftung unterscheiden. Demgemäß müssen jedenfalls die zur Heilung notwendigen Faktoren verschieden sein, je nachdem der Ort der Injektion und die Resorptionsmöglichkeit wechselt. Es dürfen somit Experimentalvergiftung mit bestimmten Giftmengen, nicht obne weiteres den klinischen Intoxikationsverhältnissen am Menschen gleichgesetzt werden. 
Der Diphtheriebazillus wirkt dureh sein Toxin, welches dureh das spezifische Antitoxin in vitro, wie in vivo neutralisiert und in eine für den Körper unschädliehe Verbindung tubergeführt wird. Dieses Antitoxin wird dargestellt von den durch Immunisierung überproduzierten und in die Blutbahn abgestoßenen Zellrezep-

Kurve III.

Einfluß der Medikamente auf den Blutdruck am leicht vergifteten Tier (28 Stunden nach subkutaner Injektion von 0,03 Toxin.)
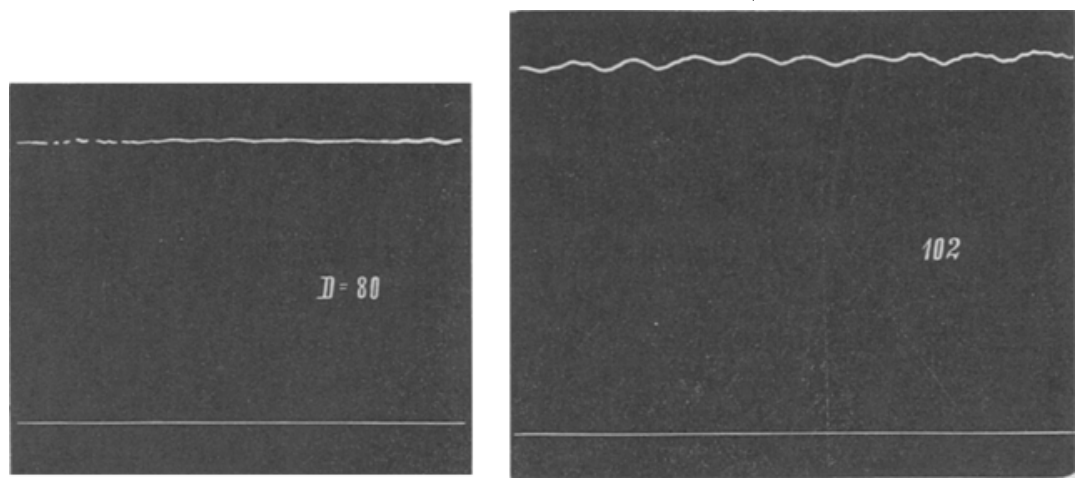

Coffein natr. salicyl. 0,01

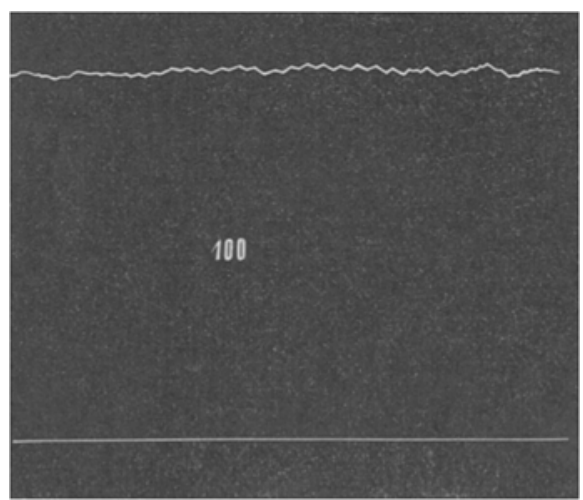

Digalen $1,0 \mathrm{ccm}$

toren, welehe sich mit dem Toxin verbinden. Die zu lösende Frage besteht darin, klarzustellen, wie sich die definitive Bindung des Giftes an die Zellen des Organismus, zur Neutralisierung des Toxins durch Antitoxin verbält. Mit anderen Worten: gibt es eine Möglichkeit, schon verankertes. Toxin von den Zellen des Organismus durch Antitoxin loszureißen? Nur in diesem Faktum allein kann man eine echte Heilung erblicken, während 
Beitrăge zur Kenntnis der Diphtherievergiftung und ihrer Behandlung. 219 die Neutralisierung des noch im Blute kreisenden Toxins eine prophylaktische, d. h. eine Sehutzwirkung darstellt. Die Frage, ob wir mit den Kurve III

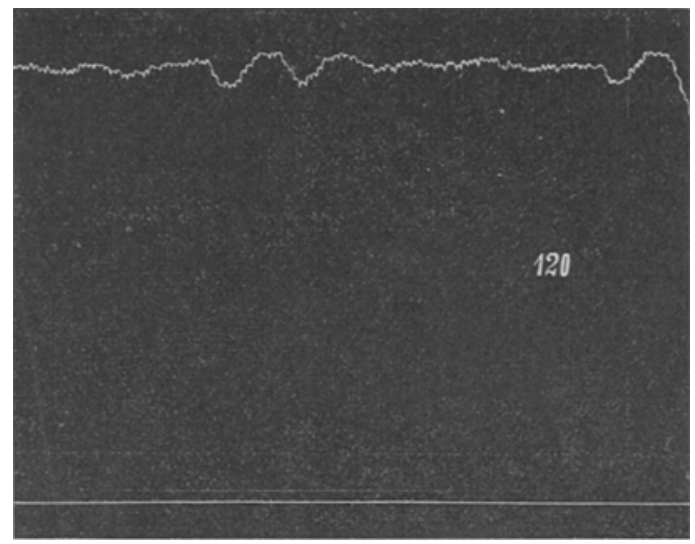

Strophantin 0,0002

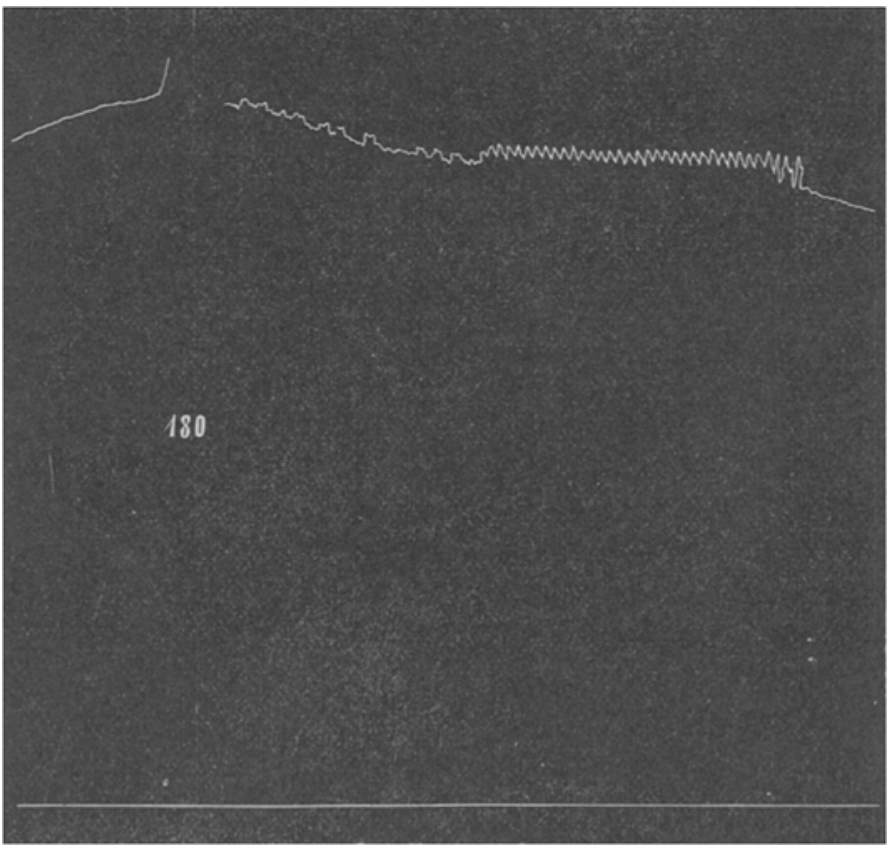

Adrenalin Kochsalzinfusion.

Serumeinspritzungen unsere Diphtheriekranken schïtzen oder heilen, ist wegen der bestehenden Infektion noch schwieriger zu entscheiden, als es das mit fertigem Gift angestellte Tierexperiment es erlaubt. 
Über diesen Gegenstand liegen nur wenige, wenn auch um so bedeutungsvollere Arbeiten vor, welche von Marx (10), Dönitz (11), und Craveilhier (12) angestellt worden sind.

Marx, der vornehmlich die Frage entseheiden wollte, ob das gleiche Serum einen, von einander unabhängigen sehü tzenden und heilenden Effekt ausüben kann, kommt zum Schlusse, daß allein der Gehalt von Antitoxineinheiten, sowohl den kurativen, wie anch den schïtzenden Einfluß bedingt und mit der gleichen Anzahl Antitoxineinheiten stets der gleiche Effekt erreicht wird, gleichgültig ob sie einem 10 fachen oder 1150 fachen Serum entstammen. Er fand, daß bei subkutaner Injektion drei Stunden, bei intravenöser Einspritzung eine Stunde die Grenzfrist bedenten, nach weleber durch Serum Heilung herbeigefübrt werden kann.

Dönitz führte ähnliche Versuche, analog seinen bekannten Tetanusheilversuchen aus und fand, wie er gelegentlich des Madrider Kongresses mitteilte, daß vornehmlich die Größe der Toxindosis die Länge der Frist zwischen Giftinjektion und heilender Serumeinspritzung bestimmt. Während bei $1 \frac{1}{2}$ Dosis letalis 3 Stunden vergehen dürfen, bis Serum gegeben wird, konnten die Tiere bei 60 facher Dosis nur noch nach 7 Minuten gerettet werden.

Demgegenüber stellte Cruveilhier im Institut Pasteur (Paris) fest, daß der heilende Einfluß eines Serums, wie Roux es stets betont hat, unabhängig von seinem Gehalt an Antitoxin-Einheiten ist, da es ihm gelang mit bestimmten Mengen eines minderwertigen bessere Resultate, als mit den entsprechenden Dosen eines bochwertigen Serums zu erzielen.

Unsere Versuche wurden von 3 versohiedenen Gesichtspunkten angestellt und sollten

erstens die Frage entscheiden, welche Vergiftungsfrist noch eine Heilung gestattet,

z weitens welche Unterschiede bei dieser Heilung durch Dosisunterschiede zu erzielen sind, und

drittens, welche Organschädigung bei den durch Serum scheinbar oder wirklich geretteten Tieren. als Folgeerscheinungen des Giftes zurückbleiben.

Die letzte dieser Fragen ist mittlerweile so umfangreich geworden, dafo sie in einem besonderen zweiten Teile dieser Arbeit behandelt werden soll.

Die Versuchsanordnung der ersten Gruppe war eine einfache und schloß sich, wie nachfolgende Tabelle zeigt, eng an die Marxsche Versuchsanordnung an. 
Beitrăge zur Kenntnis der Diphtherievergiftung und ihrer Behandlung. 221

a) Kaninchenversuche.

Bei intravenöser Verabfolgung der $3 \mathrm{fach}$ tödlichen Dosis an Tieren von $2000 \mathrm{~g}$ gelang es zu retten:

$$
\begin{aligned}
& \text { nach } \mathbf{5}^{\prime} \text { mit } 100 \text { A. E. } \\
& " 15^{\prime}, \quad \begin{array}{r}
100 \\
500 \\
\end{array} \\
& \begin{array}{lllll}
" & 20^{\prime} & & 500 & \\
" & 60^{\prime} & " & 400 & "
\end{array} \\
& " 240^{\prime} \text { " nicht mehr mit } 500 \text { A. E. (kurze } \\
& \text { Lebensverlängerung). }
\end{aligned}
$$

Bei subkutaner Giftinjektion (5 fach tödliche Dosis) gelang es zu retten:

$$
\begin{aligned}
& \text { nach } 6 \text { Stunden mit A. E. } 1000 \\
& " 7 \quad " \quad " 500 \text { und } 3000 \\
& \text { " } 9 \quad " \quad, \quad, 2000 \\
& " 10 \quad " \quad, \quad " 400 \text { und } 2000 \\
& " 14 " \text { konnten } 2000 \text { A. E. eine große }
\end{aligned}
$$

96 statt 24 Stunden dauernde, Lebensverlängerung bewirken. Nach 20 und 23 Stunden dagegen trat keine Verlängerung des Lebens bei gleicher Menge A.-E. ein (2000 A. E).

b) Meerschweinchenversuche.

Nach subkutaner Injektion der 6 fach tödlichem Dosis bei $250 \mathrm{~g}$ schweren Tieren gelang es

$$
\text { nach } 3 \text { Stunden mit } 5 \text { A. E. }
$$

$\begin{array}{lllll}" & 6 & " & & 150 \text {, }, 500 \text { A. E. } \\ " & 7 & " & & 500,400 \text { u. } 3000,2000 \text { A. E. } \\ " & 9 & " & & 4000 \text { A. E. dauernd zu heilen }\end{array}$

und nach 20 Stunden mit 5000 eine, allerdings geringe Verlängerung zu erzielen.

Diese Zahlen sind nicht ganz so absolut zu nehmen, wie es zuerst scheint, da, wie Marx es schon konstatierte, bei langen Vergiftungszeiten (Kaninchen und Meerschweinchen) Unregelmäßigkeiten vorkommen. Diese sind aber nicht so bäufig, daß sie die praktischen Schlußfolgerungen der übrigen Ergebnisse zu stürzen vermögen.

So kam z. B. folgendes Ergebnis vor:

Es erhalten mit 3 fach tödlicher Dosis vergiftete Meersehweinchen nach 10 Stunden $400,1000,2000,2100$ A. E. Von diesen stirbt das mit 1000 behandelte, während das mit $400 \mathrm{~A}$. E injizierte am Leben bleibt oder ein ebenso vergiftetes Meerschweinchen 
wird nach 6 Stunden durch $100 \mathrm{~A}$. E nicht geheilt, wäbrend das nach 7 Stunden mit gleicher Menge behandelte Tier davon kommt.

Die Faktoren, welehe diesen Verschiedenheiten zugrunde liegen, sind nicht näher bekannt. Man kann an Unterschiede der Resorption, an Toxinbindung im Subkutangewebe, an vorangegangene Organerkrankungen usw. denken, ohne daß man mit diesen Annahmen alles erklären könnte.

Jedenfalls resultiert aus diesen Reihen der Schluß, daß es noch in später Zeit, z. B. nach 6-8 Stunden bei subkutaner Vergiftung durch große Serumdosen gelingt, Heilung herbeizuführen. Spätere Versuche werden zu beweisen haben, ob es sich hier um echte Heilungen und nicht um Schutzwirkungen handelt. Die Dosen erreichen allerdings ungeheure Werte und würden, - will man sie auf die Therapia humana projizieren, - Werte von 10000-80000 A. E erreichen. - Diese Zahlen erscheinen unseren deutschen Anschauungen größer als andern Völkern, z. B. den Amerikanern, welche schon lange die vortreffliehe Wirkung der großen (30000 A.E) Seruminjektionen kennen gelernt haben (s. Osler) ${ }^{1}$ ).

Übereinstimmend mit den vorerwähnten Versuchen von Marx und Dönitz war somit auch von uns die große Bedeutung der Vergiftungsfrist festgestellt worden, während wir die von Dönitz unanfechtbar nachgewiesene Wichtigkeit der Toxindosis nicht noch einmal nachzuprifien für notwendig hielten.

Dagegen ist es nicht uninteressant zu prïfen, welche Rolle im Heilungsprozeb die Größe der Heildosis zu spielen berufen ist. Gelingt es - um die Frage zu präzisieren - mit einer sehr großen Serumdosis, zu einer Zeit, zu welcher die mäßige Menge versagt, Heilung zu erreichen? Die Wichtigkeit solcher Tatsachen für die Behandlung menschlicher Diphtherien liegt auf der Hand, da gerade in letzter Zeit sich vielfach der Wunsch geltend macht, obere Grenzen der Serumdosis aufzustellen.

$\mathrm{Zu}$ diesem Zwecke wurden folgende Versuchsreihen angelegt:

\section{Versuch:}

Mit der 4 fach tödlichen Giftdosis $=0,012 \mathrm{ccm}$ wurden 4 gleich große Meerschweinchen injiziert. Nach 6 Stunden erhielt das zweite Tier $100 \mathrm{~A}$. E, das dritte 150 , das vierte 500. Das Kontrolltier stirbt nach 48 Stunden, das zweite nach 52, während das dritte und vierte gesund bleiben, jedoch zunächst stark an Gewicht abnehmen.

1) Inzwischen sind Mitteilungen ron Gabriel, Pospischill und Eckert erschienen, welche zu gleichen Resultaten auf dem Wege der klinischen Beobachtung gelangen. 
Beiträge zur Kenntnis der Diphtherievergiftung und ihrer Behandlung. 223

Versuch:

Bei der gleichen Versuchsanordnung erhält nach 9 Stunden $\mathrm{Nr}$. $2=100$ A. E, Nr. $3=1000$, Nr. $4=4000$ A E. Das Kontrolltier stirbt nach 48 Stunden, Nr. 2 nach 120 Stunden, Nr. 3 nach 150 Stunden, Nr. 4 überlebt mit großem Gewichtsverlust.

Versueh:

$3 \mathrm{Kaninchen}$ von ca. $2000 \mathrm{~g}$ erhalten intravenös die 3 fach tödliche Dosis und nach einer Stunde Nr. $2=1 \mathrm{~A} \mathrm{E}$, No. $3=400 \mathrm{~A} \mathrm{E}$. Das Kontrolltier stirbt nach 32 Stunden, Nr. 2 nach 72 Stunden, No. 3 überlebt.

Versuch:

Bei gleicher Versuchsanordnung erhält:

Nr. $2=400$ A. E

Nr. 3 und Nr. 4 je 2000 A. E.

Nr. $5=1000$ A. E.

Von diesen stirbt das Kontrolltier nach 36 Stunden und Nr. 5 seltsamerweise (siehe vorher) nach 96 Stunden. Die übrigen bleiben am Leben (2 und 3 und 4 ).

Wenn somit auch hier die von Marx geschilderten Unregelmäßigkeiten bei längerer Vergiftungsfrist beobachtet wurden, so išt doch die Überlegenheit der großen Serumdosen vor den kleinen nicht zu verkennen. Es darf vor allem nicht vergessen werden, daß 1 A. E die neutralisierende Menge für 100 tödliche Dosen darstellt und die von uns als ,mittlere" bezeichnete Dosis von 100-200 A. E schon mehr als 10000 neutralisierende Dosen darstellt.

Aus diesen Reihen ist berechtigterweise der Schluß zu ziehen, daß obere Grenzen für eine Serumtherapie in Form bestimmter Zahlen, wie sie so oft mit Unrecht, zur Erleichterung der Vorschriften für den behandelnden Arzt genannt werden, sicherlich nicht berechtigt sind, so wenig, wie bei einer Diphtheriebazilleninfektion überhaupt ein genauer Maßstab für die Menge oder Stärke des resorbierten Giftes besteht. Nicht weniger wichtig ist die Art der Seruminjektion, welehe intrave nös zu erfolgen hat.

\section{III.}

Komplementgehalt der Diphtherie vergifteten Tiere.

Durch die einfache, aber sehr evidente Beobachtung, daß das Blut schwerkranker Diptherietiere, zu einem inaktiven haemolytischen System gefügt, nicht imstande war, Hämolyse hervorzurufen, vor allem aber durch Moros (13) Arbeit über den Komplementgehalt des Blutes bei Infektionskrankheiten wurden wir veranlaßt, diesen Verhältnissen etwas genauer nachzugehen. Moro hatte gefunden, daß das Komplement während der Fieberperiode in der Regel steigt, während ein Sinken desselben eine ungünstige Prognose zu stellen 
gestattet. Wir verfuhren daher zur Messung der Komplementfăhigkeit des Serums unserer Versuchstiere derart, daß wir

1. Ochsenblut (5\% Aufschwemmung),

2. inaktiviertes Serum eines mit Ochsenblut vorbehandelten Kaninchens und

3. das Serum unserer vergifteten Kaninchen in bestimmten Mengenverhältnissen zusammenbrachten und bei $37^{\circ}$ auf einander einwirken ließen.

\section{Versuch:}

1 ccm einer $5 \%$ Ochsenblutanfschwemmung $+0,02$ inaktiviertes Serum (Kaninchen mit Ochsenblut vorbehandelt) + wechselnde Mengen $(0,2-0,04)$ eines zu prüfenden Serums wurden 1 Stunde bei $37^{\circ}$, dann 24 Stunden im Eisschrank gehalten und das Resultat abgelesen.

Bei Verwendung eines normalen Serums als 3 ergab sich:

1 cem Ochsenblut $+0,01 \quad\left\{\begin{array}{l}0,3 \\ 0,2 \\ 0,1 \\ 0,075 \\ \text { Aufsehwemmung vorbehan- } \\ \text { delten Serums } \\ 0,05 \\ 0,04 \text { starke Hämolyse } \\ 0,025 \text { schwachedoch deutliche Hämolyse. }\end{array}\right.$

Bei Verwendung des Serums eines diphtherie-vergifteten Tieres (8 Stunden ante mortem):

0,15 sehwache, doch deutliche Hämolyse

0,1 Spuren vom Hämolyse

$$
\text { darunter }=0=\text { ungelöst. }
$$

Bei Verwendung eines anderen diphtheriekranken Tieres (1/2 Std. a. m.)

$$
\left.\begin{array}{l}
0,4 \\
0,3 \\
0,2
\end{array}\right\} \text { Spuren von Hämolyse }
$$

Interessant and beweisend ist ein Versuch, weleher das Serum desselben Tieres vor und nach der Vergiftung benutzt: bei gleichem hämolytischen. System lösen vorher Mengen von 0,15-0,025, nachher 0,15 bis 0,1 während schon 0,075 völlig wirkungslos bleiben.

Einmal gelang es im Serum eines solehen Tieres nicht nur eine schon wesentliche Verminderung des Komplementsgehalts nachzuweisen, sondern auch zu zeigen, daß dieses Serum normales Komplement zu zerstören vermochte. 
Beitrăge zur Kenntnis der Diphtherievergiftung und ihrer Behandlung. 225

Versuch:

\begin{tabular}{|c|c|c|c|}
\hline $\begin{array}{c}\text { Krankenserum } \\
\qquad 0,5\end{array}$ & $\begin{array}{c}\text { Normalserum } \\
0,15\end{array}$ & $\begin{array}{c}\text { Amboceptor } \\
0,01\end{array}$ & $\begin{array}{c}\text { Rinderblut } 5 \% \\
1,0\end{array}$ \\
\hline$a\{0,3$ & 0,15 & & \\
\hline 0,2 & 0,15 & & \\
\hline$(0,1$ & & & \\
\hline$b\{0,05$ & 0,15 & & \\
\hline 0,09 & 0,15 & & \\
\hline
\end{tabular}

während die mit a bezeichneten Röhren ungelöst blieben, waren die b Röbren in gleichem Maße gelöst.

Dieses Phänomen, welches übrigens nur sehr unregelmäßig auftrat, wies uns darauf hin, Reagensglasversuche anzustellen, um zu entseheiden, ob die Komplementverminderung der tödlich erkrankten Tiere nur ein Symptom des Todes oder eine Eigenschaft des Diphteriegiftes als solehes darstellt. Es wurden zur Klärung dieser Frage eine große Reihe von Versuchen angestellt, indem bei einem genau austitrierten hämolytischem System bestimmte Mengen Normalserum verwendet wurden, welche vorher der Einwirkung abgemessener Mengen Diphtherietoxins ausgesetzt worden waren.

\section{Versuch.}

Rinderblut $(5 \%)$ vorbehandeltes normales Serum

Serum

Diphtheriegift Resultat

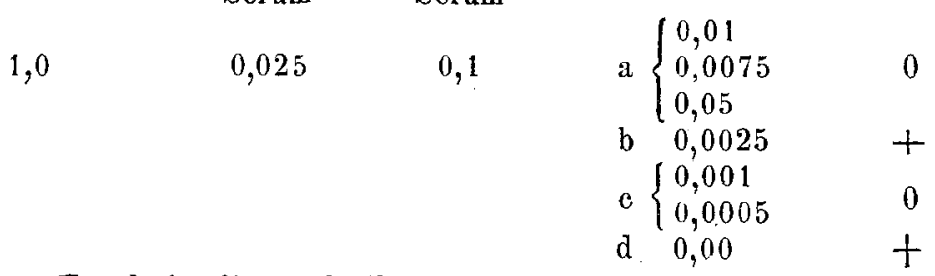

Das Ergebnis dieser Reibe, die häufig wiederholt wurde, war ein sehr auffallendes, da die größten und kleinsten Dosen Diphtherietoxins eine bemmende, die mittleren eine beschleunigende Wirkung: besaßen, da a und $c$ ungelöst, $b$ und d gelöst waren.

Bei der Eigenart des Befundes wurde sofort ein Kontrollversuch mit frischer Toluolbouillon und Diphtherietoxin angestellt und das Ergebnis war in allen Reiben das gleiche. Mittlere Dosen der mit Toluol gesättigten 2 proz. Peptonbouillon, welche allein selbst in größerer Menge nicht hämolytisch wirken, begünstigen in bestimmten, mittleren Dosen die spezifische Hämolyse.

Besonders klar tritt diese Wirkung in der Versuchsanordnung hervor, welche fallende Miengen Di-toxin einwirken läßt auf ein an und für sich ungenügendes Komplement und dieses zu einem lösenden erhebt. 
Versuch:

Rinderblut Amboceptor Normalserum kompl. Di-toxin

$$
\quad 0,01 \quad 0,05 \quad \text { a }\left\{\begin{array}{l}
0,02 \\
0,01 \\
0,0075 \\
0,005 \\
0,0025
\end{array}\right\}+
$$

Kontrolle - - 0

Während die Kontrolle ungelöst bleibt, werden die mit a bezeichneten Röhren zuerst und komplett gelöst.

Dieses Phänomen, so interessant es an und für sich ist, erschwerte das Studium der Komplementbeeinflussung durch Diphtheriegift in vitro derartig, daß diese Frage vorerst in suspenso gelassen werden mußte.

Besonders kompliziert gestalteten sich die Verhältnisse bei der Einwirkung des Diphtheriegiftes in Gestalt von Tolwolbouillon dureh die Tatsache, daß Pepton an und für sich in größeren Dosen Komplement absorbiert und Toluol eine älnliche Wirkung hat. Daher blieben auch alle Absättigungsversuche, ebenso die Zerstörung: der Toxine durch Hitze, ohne Erfolg und die Tatsache allein, daß der Komplementgehalt in vitro sinkt, wäbrend die Toluolbouillon an sich einen begünstigenden Effekt auf die spezifische Hämolyse ausübt, sind die einzigen sicheren Resultate dieser langen und zahlreichen Versucbsreihen.

Herr Professor von Dungern hatte die Guite, mir für diese Beobachtung seinen Rat zu erteilen und sie zu kontrollieren.

\section{IV.}

Resistenzverminderung der roten Blutkörperchen während der Diphtherievergiftung gegenüber anisotonischen Salzlösungen.

Der Gedanke, die Resistenz der roten Blutkörperchen diphtheriekranker Tiere zu prüfen, wurde nahegelegt durch die Tatsache, daß diphtherievergiftete Tiere bestimmten Salzlösungen (Magnesiumsulat) gegenüber eine anffallende Empfindlichkeit zeigen. Erinnern wir uns gleichzeitig der häufigen Anämie und Bämoglobinverminderung diphtheriekranker Menschen, so lag der Gedanke nahe, an eine besondere Einwirkung des Toxins auf die Erythrozyten zu denken. Sorgfältig durchgeführte Reagensglasversuche zeigten, dab ein echtes Hämolysin, im Sinne des Staphylolysins nicht in demselben enthalten ist und machten den komplizierten Weg eines indirekten Nachweises notwendig. 
Zahlreiche Arbeiten hatten den Einflub des Toxins auf die Leukozyten im Sinne einer häufigen und starken Hyperlenkozytose studiert, nur K uchargensky(14) hatte sich mit den Veränderungen der roten Blutkörperchen beschäftigt. Er konnte regelmäßig eine Verminderung ihrer Anzahl und ịhres Hämoglobingehaltes nachweisen. Resistenzveränderungen roter Blutkörperchen gegenüber Salzlösungen hat in letzter Zeit vor allem Widal (15) bei verschiedenen Lebererkrankungen beobachtet und seinen Angaben folgend verfuhren wir folgendermaßen:

Ans einer Ohrvene wurden von einem Kaninchen 5 com Blut entnommen, defibriniert und sorgfältig mit physiologischer Kochsalzlösung mehrmals gewaschen. N Nur solche Proben werden zu weiteren Versuchen verwendet, welehe durch gelbes oder farbloses Aussehen der Spülflüssigkeit anzeigten, daß Blutkörperehen nicht zugrunde gegangen sind. Die so gewonnenen Zellen werden auf $100 \mathrm{ccm}$ mittels 0,8 prozentiger Kochsalzlösung aufgefüllt und in besonders präparierte Agglutinationsgläser in Mengen von je $1 \mathrm{ccm}$ verteilt In diese Gläser $(1-14)$ wird $1 \mathrm{cem}$ einer $0,8-0,24$ proz. Kochsalzlösung gefüllt und zu dieser Mischung die vorerwähnte 5 proz. Suspension der zu prüfenden Blutkörperchen gefügt.

Die einzelnen Gläser differieren stets um $0,05 \mathrm{ccm}=1 / 20$ einer 0,8 proz. Kochsalzlösung und bilden eine feststehende brauchbare Skala. In der Regel wurde so verfahren, daß die Blutkörperehen des gleichen Tieres vor und nach der Vergiftung geprift wurden, da sich herausstellte, daß normale Tiere greifbare Unterschiede unter einander darbieten.

Folgendes Schema eines Versuchs gibt über die Blntveränderung Aufschluß:

\begin{tabular}{|c|c|c|c|c|c|c|c|}
\hline & & während & Tier vor & & & Fortsetzur & \\
\hline & der & ergiftung & der Vergiftun & & & Tier während & Tier vor \\
\hline Röhre & 1 & 0 & 0 & & & der Vergiftung d & der Vergiftung \\
\hline & 2 & 0 & 0 & Röhre & 10 & 0 & 0 \\
\hline & 3 & 0 & 0 & & 11 & 0 & 0 \\
\hline & 4 & 0 & 0 & & 12 & Spur Lösung & 0 \\
\hline & 5 & 0 & 0 & & 13 & stärkere Lösg. & 0 \\
\hline & 6 & 0 & 0 & & 14 & starke Lösung & 0 \\
\hline & 7 & 0 & 0 & & 15 & $\eta$ & 0 \\
\hline & 8 & 0 & 0 & & 16 & $\mathrm{~S}]$ & Spur Lösung \\
\hline & 9 & 0 & 0 & & 17 & stä & ärkere Lösung \\
\hline
\end{tabular}

In der Regel betrug die Differenz des normalen und Diphtherieblutes einen Abstand von 3-4 Röhren $=0,15-0,2$ einer 0,8 proz. 
Kocbsalzlösung. Einige Tiere, welehe eines sehr akuten Gifttodes (20-22 Stunden) starben, erlagen offenbar zu schnell, um die charakteristische Veränderung aufzuweisen. Es ist nicht ausgeschlossen, daß bei menschlichen Diphtheriefällen, bei denen eine lange dauernde, starke Giftresorption stattindet, dieses Phänomen noch besser ausgebildet ist, als bei der experimentellen Vergiftung. Es ist so leicht und einfach auszuführen, dab die Mühe, es auf seinen prognostisehen und diagnostischen Wert zu prüfen, sich wohl verlohnen könnte.

\section{SebluBbetrachtungen.}

Aus vorliegenden Versuchen, welche naturgemäß im Hinblick auf die menschliche Diphtherie und ihre Behandlung unternommen wurden, ergeben sich mancherlei Folgerungen über Wirkung, Anwendung und Dosierung des Heilserums, welche mit den augenblicklich gangbaren Anschauungen scheinbar arg kontrastieren.

Wenn wir aus dem ersten Abschnitt äber die Blutdrucksenkungen und ihre Behandlung gesehen haben, daß gewaltige Unterschiede in der Wirkung des Serums je nach der Menge des injizierten Antitoxins zu verzeichnen waren, wenn wir vor allem die zu diesem Zwecke angewendeten Mengen berücksichtigen, welehe für $250 \mathrm{~g}$ Meersehwein über 400 A.E. und für $2000 \mathrm{~g}$ Kaninchen über 2000 A.E. fordern, so beruhrt es seltsam, dab unsere gebräuchlichen therapeutischen Vorsehriften bei menschlicher Diphtherie nur selten Dosen von 2000 oder mehr A.E. aufweisen. Wenn es heute noeh immer Skeptiker hinsichtlich der Wirkung des Antitoxins gibt, so ist nach unserer Meinung nicht zum wenigsten diese, nach materiellen und änßeren Gründen getroffene Fixierung der Dosis dafür verantwortlich zu machen. Es gibt für die Antitoxinbehandlnng der Diphtherie, vorausgesetzt, dab sie mit karbolfreiem Serum ausgeführt wird, überhaupt keine obere Grenze. Wenn 0 sler in seinem Lehrbuch von der spezifischen Behandlung der Diphtberie sagt, daß sie zwisehen 8-70000 A.E. schwanke, so ist er unseren deutsehen Ansehauungen schon lange gewaltig vorausgeeilt. Gewiß ist es dringend wïnschenswert die spezifische Behandlung so früh als nur irgend möglich einzuleiten. Aber andererseits gibt es für eine Serumbehandlung kein „zu spät", denn experimentell ließ sich fast in allen Fällen eine Verlängerung des Lebens selbst durch späte Seruminjektionen erzielen. Resümieren wir also zunächst hinsichtlich der Dosis und des Zeitpunktes 
dahin, daß stets, selbst in verzweifelten Fällen ein Heilversuch mit einer großen Dosis (20000 bis 50000 A.E.) gemacht werden muß, so ist es nicht minder wichtig diesen Eingriff, wie ebenfalls die Amerikaner es schon seit 3 Jahren getan haben, auf intravenösem Wege auszuführen. Vorbedingung für diese Behandlungsart, welche durch Veit und seine Schtiler (16) für das Antistreptokokkenserum mit gutem Erfolge begonnen wurde, ist steriles, karbolfreies und klares Pferdeserum, welches unbedenklich in Dosen von $30-50 \mathrm{ccm}$ infundiert werden darf. Nicht alle in die Tatsache, dab damit. sicher ein Vorsprung von 3 bis 4 Stunden gewonnen wird (Dönitz), muß zu einer solchen Mabregel führen, sondern vor allem die Mögliehkeit, dab ein grober Teil des Antitoxins aufdem Resorptionswege durch Gift gebunden werdenkann, welches sich im Unterhautzellgewebe befindet. Ein Teil der Antitoxine geht so verloren, bevor er in die Blutbahn und damit an die lebenswiehtigen Organe gelangt. Der gefürehtete Spättod bei Diphtherie erfolgt in erster Linie durch Veränderungen des Herzmuskels, der Nieren und vielleicht der Leber. Diese Organe können dureh Serum gesehützt werden, selbst wenn die Zeit schon erheblich vorgeschritten ist.

Die heute herrschende Anschauung, daß das Serum anf die Kreislaufsveränderungen keinen Einfluß habe, trifft nicht zu. Wir sahen, dab der Blutdruck indirekt durch das giftneutralisierende Serum beeinflußt wird, wenn auch nur bei frühzeitiger Anwendung und sahen, daß Tiere wochenlang ohne Herzveränderungen leben, vorausgesetzt, daß die angewandte Serummenge hinreichend groß gewesen ist. Wie ist die so tief eingewurzelte Anschaunng zu erklären, daß das antitoxische Diphtherie-Serum auf Herz und Nieren nicht wirken kann, sondern nur die diphtherisehen Halsveränderungen beeinflußt? Die wahrseheinliche Erklärung dieser Anschaunng liegt in zwei Hauptgrïnden. Einmal ist, wie sehon erwähnt, die von uns angewendete Menge der Antitoxine viel zu klein, um große Wirkungen zu erzielen, sodann achten wir nur auf die lokalen sichtbaren Wirkungen, weil wir leider gewohnt sind, Diphtheriefälle nach dem Aussehen der Primärinfektion zu beurteilen: eine Anschaunng, welche für keine andere Infektion zu Recht besteht. Vergegenwärtigen wir uns, daß es sich bei der Diphtherie nicht nur um eine Affektion des Halses, sondern vor allem um eine Intoxikation des Gesamtorganismus und ibre. Folgen handelt, so erscheint es seltsam, daß alle Vorschriften bei dieser Krankheit über Anwendung und Dosierung des Serums, rom Befund des Halses ab- 
hängig gemacht werden. Es muß zugegeben werden, daß die Feststellung eventueller Progredienz des Prozesses wichtig ist und aus einer solchen auf eine hohe Toxinbildung der Bazillen geschlossen werden kann. Niemals aber darf damit, wie es so häufig geschieht, eine Vernachlässigung des Pulses und des Blutdruckes, der Herzkraft und der Nierentätigkeit (s. Teil II) Hand in Hand gehen. Der entscheidende Kampf bei der Diphtherie wird mehr im Gefäßzentrum und der Herzmuskulatar als im Halse gekämpft. Jener als leicht kontrollierbar ist nur ein geringwertiger Indikator für die Prognose und Therapie der Diphtherieintoxikation, während er für die viel weniger wichtige Infektion einen guten Maßstab abgibt. Wir haben aber bei dieser Krankheit in erster Linie die Intoxikation zu bekämpfen, wie es uns die Tatsache, daß wir in Deutschland ein rein antitoxisches Serum gebraucheu, zur Genüge lebrt.

Die Frage, ob wir recht daran tun, nicht dem Rate Rouxs, Wassermanns(18), Sclavos und anderer zu folgen und kombiniert zu immunisieren, ist bisher nicht gelöst. Viel kann mit dem bisherigen System sicher nicht verloren werden, sofern wir eine so große Menge Antitoxin im Übersehuß injizieren, daß wir imstande sind mit dem Reserveantitoxin das dauernd neugebildete Toxin abzusättigen und unschädlich zu machen. Klar ist aber aucb, daß wir, so lange wir durch bakterizides Diphtherieserum nicht direkt anf die Infektion einwirken, diesen Übersehuß notwendig gebrauchen. Mit diesem Faktum erklärt sich der manchmal ausbleibende Heileffekt, vor allem wenn nach dem von den Fabriken empfohlenen Modus der wiederbolten kleinen Injektion verfahren wird. Nach den wichtigen von Sachar off(17) im Ehrlichsehen Institut gefundenen Resultaten wissen wir, daB gerade das Pferdeserum schnell Eiweißantikörper zu bilden imstande ist, welche zugleich wie Serumeiweiß auch Antitoyin unwirksam za machen vermögen. Liegen demnach mehr als 5 Tage und weniger als 1 Jahr zwischen zwei Injektionen, so ist die letztgemachte Einspritzung, welche stets Überempfindlichkeitssymptome auslüst, völlig zwecklos.

Alle diese Momente weisen stets von neuem auf den bisher nicht genügend betonten Grundsatz, bei allen schwersten, mittelsohweren und schweren Diphtheriefällen anf einmal eine große Me nge Antitoxin, a $m$ besten intravenös, einzuftubren und in der Beurteilung des Falles sich nicht nur nach dem Verhalten des Halsbelags, sondern vor allem nach der Beschaffenheit der Kreis- 
Beitrăge zur Kenntnis der Diphtherievergiftung und ihrer Behandlung. 231

laufsorgane und des Blutdrueks zu riehten. Prognostiseh kann neben diesen Momenten auf den Komplementgehalt des Blutes und das Verhalten der Blutkörperchen Wert gelegt werden, wodurch es vielleicht gelingen wird Schlüsse auf den Grad der Intoxikation und die Resistenzfähigkeit der Organe zu ziehen.

Vor allem aber verdient hier als Behandlung des Diphtheriekollapses die neue von Heidenhain empfohlene Methode der Adrenalin-Kochsalzinfusion dringend der Beachtung, da es dank dieser vielleicht möglich ist, dem Serum die Frist zu verschaffen, Heilwirkungen zu entfalten. An der echten und sicheren Heil- und Sehutzwirkung des Serums ist nach unseren Versuchen nicht zu zweifeln, wohl aber läßt sich die Empfindung nicht abweisen, daß wir dieses wundervolle Werk v. Behrings und Ehrlichs zu frühzeitig in bestimmten und starren Grenzen fixiert und ibm so die Möglichkeit genommen haben, seine wahren Heilwirkungen in vollem Maße zu entfalten.

\section{SchluBsätze.}

1.

Die experimentelle Vergiftung mit Diphtherietoxin geht mit nachweisbarer Blutdrucksenkung einher. Dieselbe setzt nach einer in der Regel 24-30 Stunden dauernden Latenzzeit ein und schreitet danernd bis zum Tode vor. (Gottlieb; Rolly.)

\section{2.}

Es gelingt durch rechtzeitig einverleibte Dosen Heilserum die dem Diphtherietod vorangehende Drucksenkung zu verhindern, durch unzureichende Serummengen hinauszuschieben.

3.

Selbst die größte Serumgabe vermag eine bereits vorhandene Drucksenkung nicht aufzuheben.

4.

Die einzige Behandlungsart, welche am schwerkranken Tiere Momentanerfolge erzielt, ist die Adrenalinkochsalz-Infusion nach Heidenhain.

Die Heilung von Diphtherievergiftung (3fach -6 fach tödliehe Dosis) gelingt durch Injektion von Heilserum bis 9 Stunden nach subkutaner, bis 11/2 Std. nach intravenöser Injektion des Giftes.

6.

In vorgesehritteneren Stadien der Intoxikation wirken $k$ leine Serumdosen lebenverlängernd, gro B e heilend. 
232 X. Fritz MeYer: Beiträge zur Kenntnis der Diphtherievergiftung usw.

7.

Die Vergiftung geht beim Tiere mit nachweisbarer Verringerung des Komplementgehaltes einher.

8.

In Vitro vermag Diphtherietoxin in größeren Dosen Komplement $\mathrm{zu}$ vernichten.

Dieses Faktum wird zum Teil dureh das, der Peptonbouillon innewohnende Vermögen in mittleren Dosen die spezifische Hämolyse zu begünstigen, verdeckt.

9.

Die Resistenz der roten Blutkörperchen eines Diphtherie- vergifteten Tieres gegenüber anisotonischer Salzlösung ist herabgesetzt.

Literatur.

1. Berl. klin. Wochenschrift 1895 . N. 51/52.

2. Deutsch. Arch. für klin. Med. Bd. 77.

3. Zeitschrift für klinische Medizin Bd. 51. H. 1 u. 2.

4. Archiv für experim. Pathol. Bd. 72 .

5. Deutsche med. Wochenschr. 1908.

6. Medizinische Klinik 1905 N. 25.

7. Mitteilungen aus den Grenzgebieten 1908 Bd. 18.

8. Archir für klin. Medizin 1907.

9. Deutsche med. Wochenschr. 1908 N. 6 und Münchn. med. Wochenschr. N. 12.

10. Zeitschrift für Hygiene und Infektionskrankheiten $1901 \mathrm{Bd} .38$.

11. Archiv. internat. de Pbarmakodynamie 1899 t. 5.

12. Annales de l'Institut Pasteur 1905.

13. Wiener med. Wochenschrift 1908.

14. Wratsch 1904.

15. Presse medicale 1907. 3 Octobre.

16. Gynäkologentag Dresden 1907.

17. Zertralblatt für Bakteriologie Bd. 39.

18. Deutsche med. Wochenschrift 1902. 